\title{
Fortalezas y debilidades del concepto polisémico de "competencias"
}

Strengths and weaknesses of the polysemic concept of "competencies"

\section{Volumen 17, Número 3 \\ Setiembre-Diciembre}

pp. 1-30

DOI: http://dx.doi.org/10.15517/aie.v17i3.29065

\author{
Juan B. Climént Bonilla
}

Revista indizada en REDALYC, SCIELO

Revista distribuida en las bases de datos:

LATINDEX, DOAJ, $\underline{\text { REDIB }}$ IRESIE, $\underline{\text { CLASE}}$, DIALNET, SHERPA/ROMEO, QUALIS-CAPES, MIAR

Revista registrada en los directorios:

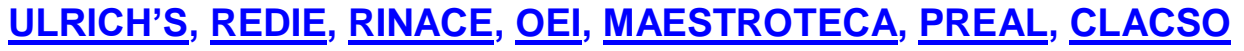




\title{
Fortalezas y debilidades del concepto polisémico de "competencias" \\ Strengths and weaknesses of the polysemic concept of "competencies"
}

\section{Juan B. Climént Bonilla}

\begin{abstract}
Resumen: Mediante los procesos de globalización en curso, la corriente a favor del fomento de las competencias ha cobrado progresiva presencia en medios académicos y laborales de muchas naciones. El principal propósito de este artículo es profundizar en el conocimiento de las fortalezas (ventajas) y debilidades (desventajas) de las propiedades comunes a una amplia variedad de significados atribuidos al término "competencias". La investigación - de carácter cualitativo - parte del análisis de una muestra fundamentada de 22 definiciones, del propio término, que fueron publicadas en un periodo de 40 años (de 1973 a 2013) por igual número de autores. En torno al concepto polisémico de las competencias, se observa la existencia de diez propiedades esenciales inherentes a su naturaleza; a saber: estructura, contexto, concepción, enfoque de formación, proceso de habituación, referencia a valores, dimensión, etapa de la vida, temporalidad y paradigma epistemológico. Se asume que el conocimiento de estas propiedades permite ponderar las fortalezas y debilidades de los acercamientos a las competencias de individuos y grupos, desde diferentes puntos de vista y para distintos fines, lo cual eleva las probabilidades de éxito de iniciativas de formación bajo condiciones particulares.
\end{abstract}

Palabras clave: competencias, desarrollo de habilidades, educación superior, formación profesional

Abstract: Throughout the ongoing processes of globalization, the current promotion of competences has gained increasing presence in academic and professional spheres of many nations. The main purpose of this article is to deepen the knowledge of the strengths (advantages) and weaknesses (disadvantages) of properties common to a wide variety of meanings attributed to the term "competences". The research -eminently qualitative- is based on the analysis of a purposive sampling of 22 definitions, of the term itself, published in a period of 40 years (19732013), by an equal number of authors. Around the polysemic concept of competencies, the existence of ten essential properties inherent to their nature is observed; namely: structure, context, conception, education and training approach, habituation process, reference to values, dimension, stage of life, impermanence and epistemological paradigm. It is assumed that knowledge of these properties allows pondering individual and collective competence approaches' strengths and weaknesses, from different points of view and purposes, which increases the success probabilities of education and training initiatives under specific conditions.

Key words: competencies, skills development, higher education, vocational training

\footnotetext{
1 Profesor Investigador de la Universidad Autónoma Metropolitana, Unidad Xochimilco, México. Doctor en Educación por la Universidad de Cornell, Estados Unidos; ha participado como consultor en diversos estudios y proyectos en materia de desarrollo rural y educación para adultos.
}

Dirección electrónica: jcliment@correo.xoc.uam.mx

Artículo recibido: 3 de diciembre, 2016

Enviado a corrección: 10 de mayo, 2017

Aprobado: 15 de mayo, 2017 


\section{Introducción}

La corriente a favor de la formación de competencias, que predomina hoy en día en medios académicos y laborales, necesariamente nos remite al artículo de David McClelland, Testing for competence rather than for "intelligence" (1973), el cual sustenta la idea de evaluar el desempeño de las personas en el ámbito de sus organizaciones y sociedades a partir de competencias probadas, en lugar de estimadores de inteligencia preestablecidos de manera genérica, como es el caso del cociente intelectual $(\mathrm{Cl})$.

Los principios operativos de la Educación Basada en Competencias (EBC) parecen tener su origen en la Acreditación de Aprendizajes Previos (Accreditation of Prior Learning), en el Reino Unido, durante la primera mitad del Siglo XIX (Nyatanga, Forman y Fox, 1998); sin embargo, es hasta las últimas décadas del Siglo XX en que, con el vertiginoso avance de las nuevas tecnologías de la información y la comunicación (TIC), la propuesta de McClelland de probar las competencias de las personas mediante instrumentos de evaluación acordesdio pie a la invención y desarrollo de grandes tecnologías sociales para la gestión de competencias individuales en entidades socioeconómicas y geopolíticas de particular interés.

Sobre la marcha de los procesos globalizadores, que entrañan la "sociedad del conocimiento" y la "era de la informática", el desarrollo de las instancias e iniciativas que promueven el fomento de las competencias a escala masiva, se ha abocado al desarrollo tecnológico de elementos y mecanismos de cambio (instrumentos estandarizados de evaluación, sistemas de normalización y certificación, marcos de calificaciones, grandes bases de datos), más que al conocimiento del origen y la naturaleza de las competencias como constructos complejos del aprendizaje de las personas a lo largo de la vida; al punto que el significado de las competencias se ha relegado por décadas a las definiciones conceptuales de distintos autores y organismos. Pese a esta situación, el análisis de diversas definiciones, en materia de competencias individuales y colectivas, constituye una fuente de información fundamental para adentrarse en el complicado mundo de las competencias sobre la base de los significados y las propiedades que se les atribuyen.

El presente artículo se desarrolla mediante una investigación cualitativa, centrada en el análisis individual y conjunto de 22 definiciones del término competencias, publicadas en el transcurso de cuatro décadas (de 1973 a 2013). Dicha investigación está vinculada con estudios previos, del mismo autor, sobre el tema del significado y las propiedades esenciales de las competencias en la formación de individuos y grupos. 
Las definiciones parten de una muestra fundamentada de los significados atribuidos a las competencias, en busca, primero, de sus propiedades esenciales - tanto comunes o dominantes, como particulares o diferentes-; y segundo, de las fortalezas y debilidades concomitantes a dichas propiedades en relación con cada definición y el total de ellas. Su recopilación se realizó por medio de una extensa revisión de libros especializados, revistas académicas y de investigación, y documentos que dan buena cuenta de la diversidad de versiones y posturas alrededor del vocablo competencias durante un período de grandes y acelerados cambios tecnológicos, sociales y medioambientales. El principal propósito de este artículo es mejorar la comprensión de lo que se entiende por competencias, más allá de interpretaciones conceptuales, a través del análisis particular y conjunto de las fortalezas y debilidades de algunas de sus propiedades esenciales.

\section{Marco teórico}

A raíz de los procesos globalizadores de los últimos tiempos, vinculados a la corriente político-económica del neoliberalismo —nuevo liberalismo o liberalismo tecnocrático-, un amplio número de países alrededor del mundo adoptó el término competencias para fundamentar e introducir reformas a sus sistemas de formación en áreas clave del desarrollo económico y social, como educación, trabajo y empleo. La incorporación de estas reformas se llevó a cabo mediante instrumentos y mecanismos de gestión, evaluación, certificación, acreditación y aseguramiento de la calidad, con base en competencias estandarizadas. Entre estos países podría citarse, por ejemplo: Reino Unido (1986), Australia (1990) y México (1996); Alemania, Francia, España, Colombia y Argentina (2000); Estados Unidos, Canadá, Japón Chile y Brasil (2000) (Insaforp, s.f.). Asimismo, la gran magnitud y grado de sofisticación alcanzados por dichas reformas quedan de manifiesto en complejos sistemas de calificaciones, como los establecidos en los siguientes países:

- Irlanda: Calidad y Calificaciones Irlanda (Quality and Qualifications Ireland, QQI).

- Escocia: Autoridad Escocesa de Calificaciones (Scottish Qualifications Authority, SQA).

- Australia: Marco Australiano de Calificaciones (Australian Qualifications Framework, $A Q F)$.

- Nueva Zelanda: Autoridad de Calificaciones Neozelandesa (New Zealand Qualifications Authority, NZQA).

- España: Sistema Nacional de las Cualificaciones y Formación Profesional (SNCFP). 
- México: Consejo Nacional de Normalización y Certificación de Competencias Laborales (CONOCER).

Independientemente del país, sector de la sociedad y carácter de la organización de que se trate, las iniciativas basadas en competencias siempre parten de la definición, de lo que se entiende y da a entender por estas en términos conceptuales de índole cualitativa. De esta premisa se desprenden otras que proporcionan las bases metodológicas de la presente investigación:

- El análisis del concepto polisémico de competencias proporciona una teoría fundamentada (grounded theory) o inductiva (inductive theory) de lo que son estas y de lo que representan. Así, la teoría de las competencias proviene de los significados que se les atribuyen y no de una teoría que les es impuesta (Miles y Huberman, 1984).

- La teoría fundamentada de las competencias debe aportar al conocimiento, primero, de sus propiedades, y segundo, de las fortalezas y debilidades adjudicadas a tales propiedades.

- El método de investigación cualitativa -aquí utilizado- se desarrolla y cambia conforme se desarrolla el propio trabajo en el contexto de la solución de problemas (Strauss, 1987).

Mientras de las definiciones de competencias destaca su carácter cualitativo - como inmanente del conocer subjetivo-, de lo que las competencias objetivamente son queda de manifiesto su naturaleza sistémica: conjunto de elementos —biológicos y no biológicosque se interrelacionan e interactúan con determinado fin o propósito al que se le confiere cierto mérito o valor, bajo apreciaciones cualitativas y/o cuantitativas de sus evidencias, por parte de las entidades las sociales y económicas involucradas. Sobre la naturaleza sistémica de las competencias es pertinente plantear las siguientes premisas:

- Cada teoría o marco conceptual sobre las competencias se sustenta en una metateoría (paradigma o marco conceptual mayor) que, de manera implícita, le confiere propiedades ontológicas (sobre su contexto o realidad), epistemológicas (sobre sus conocimientos) y axiológicas (sobre sus valores). De modo que estas propiedades (elementos, cualidades, atributos) son inherentes -y por consiguiente, esenciales - a su naturaleza desde su concepción hasta su uso y aplicación.

- Toda definición de competencias es un acercamiento parcial y fragmentario del conjunto de elementos constitutivos (sistema). 
- A todas las competencias conciernen - se adviertan o no- sus propiedades esenciales.

Muchas de las publicaciones (libros, artículos científicos y de divulgación, documentos técnicos, planes y programas de estudio) sobre el tema de las competencias se circunscriben a asuntos de orden taxonómico, aplicativo o utilitario. En contraparte, sus propiedades esenciales y las implicaciones de éstas para el aprendizaje y la educación, reciben mucha menor atención de la que amerita su extenso y complejo conocimiento.

\section{Metodología}

Sobre los principios del paradigma sistémico/naturalista (Guba y Lincoln, 1983) y las bases del marco teórico expuesto, la metodología de investigación comprendió tres etapas, cada una desarrollada en el artículo bajo el apartado temático correspondiente. La primera de ellas consistió en la obtención de una muestra fundamentada de definiciones de competencias, publicadas entre las décadas de 1970 y 2010. Las fuentes revisadas fueron extensas y diversas, desde libros especializados, artículos científicos y ensayos relevantes con respecto al tema, hasta documentos institucionales nacionales e internacionales, entre otras más. De las definiciones encontradas, se seleccionaron 22 , de igual número de autores; para ello se consideró: fecha de publicación, interés, interrelaciones, originalidad, propiedades y autoría.

De esta manera se obtuvo una muestra fundamentada y representativa de la diversidad de versiones publicadas sobre el vocablo competencias, con la que se integró una base de datos cualitativos conformada por 22 campos de información. A partir del análisis particular y conjunto de las definiciones seleccionadas, se procedió a identificar, en una segunda etapa, la presencia o ausencia de las principales propiedades de las competencias; es decir, los atributos epistemológicos, axiológicos y ontológicos que los 22 autores les conceden. Esta tarea permitió, a su vez, argumentar y validar el racional de cada propiedad como tal a través de diferentes descriptores. Con el propósito de generar una extensa combinación de elementos para un examen sistemático y de fondo de las propiedades identificadas, se utilizó una matriz de análisis morfológico (Delp, Thesen, Motiwalla y Seshadri, 1977). Consecuentemente, la base de datos pasó de 22 a 484 campos de información.

Por último, en la tercera etapa, se examinaron las fortalezas (ventajas) y debilidades (desventajas) de cada una de las diez propiedades observadas a partir de sus respectivos 
descriptores y dentro de una matriz de 42 campos de información cualitativa. De este procedimiento se derivan los principales hallazgos y aportaciones que ofrece el artículo en lo concerniente al propósito central de la investigación realizada.

\section{Alcances y límites del concepto "competencias"}

En correspondencia con la metodología adoptada, durante la primera etapa de investigación, se conformó una amplia y variada relación de 22 definiciones sobre competencias, publicadas por el mismo número de autores en el curso de cuatro décadas (1970-2010); esto es, durante un periodo donde el movimiento a favor de la formación (educación, capacitación, experiencia) basada en competencias cobró gran auge en distintos países y regiones del mundo para hacer frente, o incorporarse, a los procesos de globalización (política, económica, social, cultural y tecnológica) en curso. A continuación, aparece el listado de las 22 definiciones seleccionadas, el cual deja ver, en un primer acercamiento de análisis, las similitudes y diferencias de las propiedades atribuidas a las competencias por los distintos autores:

1. Habilidades de trabajo que determinan un desempeño competente en el empleo (McClelland, 1973, p. 7).

2. "Característica subyacente de una persona que resulta en desempeño efectivo y/o superior en el empleo" (Klemp, 1980, citado en Boyatzis, 1982, p. 21).

3. Característica subyacente de una persona, por ejemplo: "un motivo, un rasgo, una habilidad, un aspecto de la imagen propia o del papel social, o un cuerpo de conocimiento que él o ella usa [en el trabajo]" (Boyatzis, 1982, p. 21).

4. Habilidad para desempeñar actividades al nivel esperado en el empleo (Lloyd y Cook, 1993, p. 14).

5. Conjunto de patrones -o dimensiones - de conducta que la persona implicada debe llevar a un puesto de trabajo para desempeñar sus tareas y funciones de manera competente -es decir, de acuerdo con los requerimientos fijados; con competencia (competence)— (Woodruffe, 1993, pp. 29, 35).

6. Característica subyacente de un individuo, causalmente relacionada con criterios (estándares) de rendimiento efectivo o superior en una situación o trabajo (Spencer y Spencer, 1993, p. 9). 
7. Estándares de desempeño, en el aprendizaje, que la mayoría de los estudiantes (de educación técnica y vocacional) puede alcanzar, y sirven a evaluadores como elementos consistentes de juicio (McDonald, Boud, Francis y Gonczi, 2000, p. 16).

8. Mulder plantea la definición de competencias, bajo los siguientes conceptos:

Capacidad de una persona (o una organización) para alcanzar logros específicos. Las competencias personales comprenden capacidades integradas orientadas al desempeño, que consisten en conjuntos de estructuras de conocimientos, y también de capacidades cognitivas, afectivas y —donde se necesitan- psicomotoras, así como de actitudes y valores, que se requieren para realizar tareas, resolver problemas y, en general, para funcionar eficazmente en cierta profesión, organización, posición o papel. (Mulder, 2001, citado en Biemans, Nieuwenhuis, Poell, Mulder y Wesselink, 2004, p. 530)

9. Capacidad de satisfacer demandas o llevar a cabo tareas con éxito, constituida de dimensiones cognitivas y no cognitivas (OECD, 2002, p. 8).

10. La competencia profesional comprende el ejercicio habitual y juicioso de cuatro funciones básicas: a) la cognitiva —adquisición y uso de conocimientos para resolver problemas de la vida real-; b) la integrativa —uso articulado y coherente de datos e información especializada de diversos campos del conocimiento afines a la profesión-; c) la relacional —comunicación efectiva con los actores sociales involucrados-; y d) la afectiva/moral —conducción sobre la base de valores éticos y humanos-. "La competencia profesional puede desarrollarse, es transitoria y depende del contexto" (Epstein y Hundert, 2002, pp. 226-227).

11. "Capacidad para desarrollar en forma idónea una función o tarea [técnicoprofesional], que implica un conjunto de conocimientos, habilidades y actitudes que se integran para alcanzar el desempeño exitoso, en función de criterios de calidad preestablecidos" (Núñez y Rojas, 2003, p. 70).

12. Las tareas laborales en que una persona debe ser competente (Dainty, Cheng y Moore, 2005, p. 40).

13. "Un conjunto de comportamientos sociales, afectivos y habilidades cognoscitivas, psicológicas, sensoriales y motoras que permiten [a alumnos y estudiantes] llevar a cabo adecuadamente un papel, un desempeño, una actividad o una tarea" (Argudín, 2005, p. 15). 
14. Desde la perspectiva de Fernández-Salinero:

La competencia colectiva busca la complementariedad y el encadenamiento de competencias [individuales]. La puesta en práctica de las competencias de cada actor está relacionada con la competencia de los demás actores de la cadena. Sólo en la medida en que cada individuo encuentra competencias complementarias a las suyas, podrá poner estas últimas plenamente en práctica. (Fernández-Salinero, 2006, p. 144)

15. Combinación de conocimientos, capacidades, habilidades, actitudes y valores que se requieren para la comprensión y transformación de una realidad compleja, de entre todo el universo de saberes relacionados con dicha realidad (Mateo, 2006, citado en Mir, 2006).

16. "Una interacción reflexiva y funcional de saberes — cognitivos, procedimentales, actitudinales, y metacognitivos - enmarcada en principios valorales, que genera evidencias articuladas y potencia actuaciones transferibles a distintos contextos, apoyadas en conocimiento situacional, identificados a través de evidencias transformadoras de la realidad" (Cázares y Cuevas, 2007, p. 18).

17. "Un conjunto de conocimientos, habilidades, destrezas y valores en un contexto socio-histórico específico, que permite a la persona [...] resolver los 'problemas' satisfactoriamente" (Pimienta, 2008, p. 25).

18. "Capacidad de una persona para poner en práctica adecuadamente los resultados de aprendizaje en un contexto concreto (educación, trabajo o desarrollo personal o profesional)" (Cedefop, 2008; citado por Cedefop, 2014, p. 48).

19. [Se entiende por competencias] "la combinación de conocimientos, habilidades (intelectuales, manuales, sociales, etc.), actitudes y valores que capacitarán al titulado para afrontar con garantías la resolución de problemas o la intervención en un asunto, en un contexto académico, profesional o social determinado" (Gutiérrez y de Pablos, 2010, p. 333).

20. Estándares que especifican el nivel de conocimientos y habilidades necesarios para realizar con éxito, en el mundo laboral, funciones adecuadas para cada grupo ocupacional (Comisión Europea, s.f.).

21. En el ámbito de la educación superior, suponen cierto grado de pericia y habilidad en los individuos que las poseen; se basan en conocimientos, habilidades, actitudes y aptitudes; y pueden adquirirse, desarrollarse o perderse. Representan 
un conjunto de atributos individuales puestos en juego en una variedad de situaciones y circunstancias. Conllevan un doble significado, asociado a su validez y confiabilidad, en el sentido de que existe un registro del seguimiento de su desempeño y de que el individuo tiene la capacidad para desempeñarse bien en el futuro. Su formación comprende, además del conocimiento experto (técnicocientífico) en determinado campo de estudio, áreas de los dominios ocupacional, social y personal, de suerte que pueden referirse lo mismo a logros esperados que a una buena adaptación (Braun, Woodley, Richardson y Leidner, 2012, basados en Weinert, 2001, y Masten y Coatsworth, 1998).

22. "Actuaciones integrales para identificar, interpretar, argumentar y resolver problemas del contexto, desarrollando y aplicando de manera articulada diferentes saberes (saber ser, saber convivir, saber hacer y saber conocer), con idoneidad, mejoramiento continuo y ética" (Tobón, 2013, p. 93).

\section{Propiedades esenciales}

En dos primeros estudios relacionados con las propiedades esenciales de las competencias se identificaron y analizaron, en uno (Climént, 2012a), cuatro propiedades: a) referencia a valores (explícita o implícita), b) contexto (laboral, educativo y/o social), c) concepción (del lado del individuo y/o del lado de terceros) y d) dimensión (individual y/o colectiva); y en otro (Climént, 2012b), seis propiedades: a) cualidades individuales (capacidades, conocimientos, habilidades, valores, comportamientos), b) desempeño (eficacia, eficiencia, efectividad, logro), c) contexto de participación (trabajo/empleo y otros), d) comprensión y transformación de la realidad (política, social, cultural, económica, medioambiental), e) estándares de evaluación (presentes o ausentes) y f) racional epistemológico (científico/racionalista y/o sistémico/naturalista).

En el primer caso, el análisis comprendió una muestra de 17 definiciones, publicadas entre 1973 y 2008; y en el segundo, una muestra de 11, publicadas entre 1973 y 2006 . Sobre la base de los anteriores estudios, el marco de análisis conceptual se amplió a 22 definiciones de competencias, las cuales cubren un lapso de cuatro décadas (de 1973 a 2013).

Tras el análisis de las 22 definiciones que conformaron la muestra de conceptos (campos de información) sobre el significado de las competencias en el curso de las últimas cuatro décadas, se retomaron siete de las propiedades esenciales identificadas previamente: cuatro del primer estudio (Climént, 2012a): a) referencia a valores b) contexto, c) concepción y 
d) dimensión; y tres del segundo (Climént, 2012b): a) estructura, b) enfoque de formación y c) paradigma epistemológico. A estas siete propiedades se agregaron tres más, debido a su consistencia con el significado y la naturaleza de las competencias: a) proceso de habituación, b) etapa de la vida y c) temporalidad, con lo que sumaron un total de diez. El Cuadro 1 muestra de manera sinóptica las diez propiedades señaladas con sus respectivos descriptores. De tal modo, se obtuvo una matriz con 484 campos de información, correspondientes a los 22 descriptores de las diez propiedades, por cada una de las 22 definiciones examinadas.

Cuadro 1

Propiedades de las competencias en la esfera de diversos planteamientos conceptuales (primera parte)

\begin{tabular}{|c|c|c|c|c|c|c|c|c|c|c|c|c|c|}
\hline \multicolumn{3}{|c|}{ Definición } & \multicolumn{2}{|c|}{ Estructura } & \multicolumn{3}{|c|}{ Contexto } & \multicolumn{2}{|c|}{ Concepción } & \multicolumn{2}{|c|}{$\begin{array}{l}\text { Enfoque de } \\
\text { formación }\end{array}$} & \multicolumn{2}{|c|}{$\begin{array}{l}\text { Proceso de } \\
\text { habituación }\end{array}$} \\
\hline No & Autor & Año & $\mathbf{a}$ & b & $\mathbf{a}$ & b & c & a & B & a & b & a & b \\
\hline 1 & McClelland & 1973 & & $\checkmark$ & $\checkmark$ & & & $\checkmark$ & & $\checkmark$ & & & $\checkmark$ \\
\hline 2 & Klemp & 1980 & & $\checkmark$ & $\checkmark$ & & & $\checkmark$ & & $\checkmark$ & & & $\checkmark$ \\
\hline 3 & Boyatzis & 1982 & & $\checkmark$ & $\checkmark$ & & & $\checkmark$ & & $\checkmark$ & & & $\checkmark$ \\
\hline 4 & Lloyd y Cook & 1993 & & $\checkmark$ & $\checkmark$ & & & $\checkmark$ & & $\checkmark$ & & & $\checkmark$ \\
\hline 5 & Woodruffe & 1993 & $\checkmark$ & & $\checkmark$ & & & $\checkmark$ & $\checkmark$ & & $\checkmark$ & & $\checkmark$ \\
\hline 6 & Spencer y Spencer & 1993 & $\checkmark$ & & $\checkmark$ & $\checkmark$ & $\checkmark$ & $\checkmark$ & $\checkmark$ & $\checkmark$ & & & $\checkmark$ \\
\hline 7 & McDonald et al. & 2000 & $\checkmark$ & & & $\checkmark$ & & & $\checkmark$ & $\checkmark$ & & & $\checkmark$ \\
\hline 8 & Mulder & 2001 & & $\checkmark$ & $\checkmark$ & $\checkmark$ & & $\checkmark$ & & & $\checkmark$ & & $\checkmark$ \\
\hline 9 & OCDE & 2002 & & $\checkmark$ & $\checkmark$ & $\checkmark$ & $\checkmark$ & $\checkmark$ & & & $\checkmark$ & & $\checkmark$ \\
\hline 10 & Epstein y Hundert & 2002 & & $\checkmark$ & $\checkmark$ & $\checkmark$ & $\checkmark$ & $\checkmark$ & $\checkmark$ & & $\checkmark$ & $\checkmark$ & \\
\hline 11 & Núñez y Rojas & 2003 & $\checkmark$ & & $\checkmark$ & $\checkmark$ & & $\checkmark$ & & & $\checkmark$ & & $\checkmark$ \\
\hline 12 & Dainty, Cheng y Moore & 2005 & & $\checkmark$ & $\checkmark$ & & & & $\checkmark$ & & $\checkmark$ & & $\checkmark$ \\
\hline 13 & Argudín & 2005 & & $\checkmark$ & & $\checkmark$ & & $\checkmark$ & & & $\checkmark$ & & $\checkmark$ \\
\hline 14 & Fernández-Salinero & 2006 & & $\checkmark$ & $\checkmark$ & $\checkmark$ & $\checkmark$ & $\checkmark$ & & & $\checkmark$ & & $\checkmark$ \\
\hline 15 & Mateo & 2006 & & $\checkmark$ & $\checkmark$ & $\checkmark$ & $\checkmark$ & $\checkmark$ & & & $\checkmark$ & & $\checkmark$ \\
\hline 16 & Cázares y Cuevas & 2007 & & $\checkmark$ & $\checkmark$ & $\checkmark$ & $\checkmark$ & $\checkmark$ & & & $\checkmark$ & & $\checkmark$ \\
\hline 17 & Pimienta & 2008 & & $\checkmark$ & & $\checkmark$ & & $\checkmark$ & & & $\checkmark$ & & $\checkmark$ \\
\hline 18 & Cedefop & 2008 & & $\checkmark$ & $\checkmark$ & $\checkmark$ & $\checkmark$ & $\checkmark$ & & & $\checkmark$ & & $\checkmark$ \\
\hline 19 & Gutiérrez y de Pablos & 2010 & & $\checkmark$ & $\checkmark$ & $\checkmark$ & $\checkmark$ & $\checkmark$ & & & $\checkmark$ & & $\checkmark$ \\
\hline 20 & Comisión Europea & $\mathrm{s} / \mathrm{f}$ & $\checkmark$ & & $\checkmark$ & & & & $\checkmark$ & & $\checkmark$ & & $\checkmark$ \\
\hline 21 & Braun et al. & 2012 & & $\checkmark$ & & $\checkmark$ & & $\checkmark$ & $\checkmark$ & & $\checkmark$ & & $\checkmark$ \\
\hline 22 & Tobón & 2013 & & $\checkmark$ & $\checkmark$ & $\checkmark$ & $\checkmark$ & $\checkmark$ & & & $\checkmark$ & & $\checkmark$ \\
\hline
\end{tabular}

Estructura: a) estandarizada, b) no estandarizada; Contexto: a) laboral, b) educativo, c) social; Concepción: a) del lado del individuo (provisión), b) del lado de terceros (demanda); Enfoque de formación: a) con base en habilidades, b) con base en competencias; Proceso de habituación: a) advertido, b) inadvertido.

Fuente: Elaboración propia a partir de Climént (2012a y 2012b). 
Cuadro 1

Propiedades de las competencias en la esfera de diversos planteamientos conceptuales (segunda parte)

\begin{tabular}{|c|c|c|c|c|c|c|c|c|c|c|c|c|c|}
\hline \multicolumn{3}{|c|}{ Definición } & \multicolumn{2}{|c|}{$\begin{array}{l}\text { Referencia a } \\
\text { valores }\end{array}$} & \multicolumn{2}{|c|}{ Dimensión } & \multicolumn{3}{|c|}{$\begin{array}{c}\text { Etapa de la } \\
\text { vida }\end{array}$} & \multicolumn{2}{|c|}{$\begin{array}{l}\text { Tempora- } \\
\text { lidad }\end{array}$} & \multicolumn{2}{|c|}{ Paradigma } \\
\hline No & Autor & Año & $a$ & $b$ & $a$ & $b$ & $a$ & $b$ & $c$ & $a$ & $b$ & $a$ & $b$ \\
\hline 1 & McClelland & 1973 & & $\checkmark$ & $\checkmark$ & & & $\checkmark$ & $\checkmark$ & & $\checkmark$ & $\checkmark$ & \\
\hline 2 & Klemp & 1980 & & $\checkmark$ & $\checkmark$ & & & $\checkmark$ & $\checkmark$ & & & $\checkmark$ & \\
\hline 3 & Boyatzis & 1982 & & $\checkmark$ & $\checkmark$ & & & $\checkmark$ & $\checkmark$ & & $\checkmark$ & --- & $\begin{array}{ll}-- \\
\end{array}$ \\
\hline 4 & Lloyd y Cook & 1993 & & $\checkmark$ & $\checkmark$ & & & $\checkmark$ & $\checkmark$ & & $\checkmark$ & $\checkmark$ & \\
\hline 5 & Woodruffe & 1993 & & $\checkmark$ & $\checkmark$ & & & $\checkmark$ & $\checkmark$ & & $\checkmark$ & $\checkmark$ & \\
\hline 6 & Spencer y Spencer & 1993 & & $\checkmark$ & $\checkmark$ & & & $\checkmark$ & $\checkmark$ & & $\checkmark$ & $\checkmark$ & \\
\hline 7 & McDonald et al. & 2000 & & $\checkmark$ & $\checkmark$ & & & $\checkmark$ & & & $\checkmark$ & $\checkmark$ & \\
\hline 8 & Mulder & 2001 & $\checkmark$ & & $\checkmark$ & $\checkmark$ & & $\checkmark$ & $\checkmark$ & & $\checkmark$ & $\checkmark$ & \\
\hline 9 & OCDE & 2002 & & $\checkmark$ & $\checkmark$ & & $\checkmark$ & $\checkmark$ & $\checkmark$ & & $\checkmark$ & $\checkmark$ & \\
\hline 10 & Epstein y Hundert & 2002 & $\checkmark$ & & $\checkmark$ & & & $\checkmark$ & $\checkmark$ & $\checkmark$ & . & $\checkmark$ & $\checkmark$ \\
\hline 11 & Núñez y Rojas & 2003 & & $\checkmark$ & $\checkmark$ & & & $\checkmark$ & $\checkmark$ & & $\checkmark$ & $\checkmark$ & \\
\hline 12 & Dainty, Cheng y Moore & 2005 & & $\checkmark$ & $\checkmark$ & & & $\checkmark$ & $\checkmark$ & & $\checkmark$ & $\checkmark$ & \\
\hline 13 & Argudín & 2005 & & $\checkmark$ & $\checkmark$ & & $\checkmark$ & $\checkmark$ & & & $\checkmark$ & $\checkmark$ & \\
\hline 14 & Fernández-Salinero & 2006 & & $\checkmark$ & $\checkmark$ & $\checkmark$ & & $\checkmark$ & $\checkmark$ & & $\checkmark$ & $\checkmark$ & \\
\hline 15 & Mateo & 2006 & $\checkmark$ & & $\checkmark$ & & & $\checkmark$ & $\checkmark$ & & $\checkmark$ & & $\checkmark$ \\
\hline 16 & Cázares y Cuevas & 2007 & $\checkmark$ & & $\checkmark$ & & $\checkmark$ & $\checkmark$ & $\checkmark$ & & $\checkmark$ & & $\checkmark$ \\
\hline 17 & Pimienta & 2008 & $\checkmark$ & & $\checkmark$ & & $\checkmark$ & $\checkmark$ & $\checkmark$ & & $\checkmark$ & & $\checkmark$ \\
\hline 18 & Cedefop & 2008 & & $\checkmark$ & $\checkmark$ & & $\checkmark$ & $\checkmark$ & $\checkmark$ & & $\checkmark$ & & $\checkmark$ \\
\hline 19 & Gutiérrez y de Pablos & 2010 & $\checkmark$ & & $\checkmark$ & & & $\checkmark$ & $\checkmark$ & & $\checkmark$ & & $\checkmark$ \\
\hline 20 & Comisión Europea & $\mathrm{s} / \mathrm{f}$ & & $\checkmark$ & $\checkmark$ & & & $\checkmark$ & $\checkmark$ & & $\checkmark$ & $\checkmark$ & \\
\hline 21 & Braun et al. & 2012 & & $\checkmark$ & $\checkmark$ & & & $\checkmark$ & & $\checkmark$ & & $\checkmark$ & $\checkmark$ \\
\hline 22 & Tobón & 2013 & $\checkmark$ & & $\checkmark$ & & $\checkmark$ & $\checkmark$ & $\checkmark$ & & $\checkmark$ & & $\checkmark$ \\
\hline
\end{tabular}

Referencia a valores: a) explícita, b) implícita; Dimensión: a) individual, b) colectiva; Etapa de la vida: a) niñez, b) juventud, c) adultez; Temporalidad: a) declarada, b) tácita; Paradigma epidemiológico: a) científico/racionalista, b) sistémico/naturalista.

Fuente: Elaboración propia a partir de Climént (2012a y 2012b).

A continuación, se examinan las particularidades de cada una de las diez propiedades esenciales dentro de la amplia gama de atributos conferidos a las competencias de las personas. De este examen se desprenden los diferentes descriptores para cada propiedad:

\subsection{Estructura}

La corriente global en pro del fomento de las competencias individuales parte de la instrumentación sistematizada (local, nacional, regional, internacional) de referentes estandarizados de desempeño, lo cual, en gran medida, explica la tendencia a asociar el enfoque de competencias, y las competencias mismas, con prácticas generalizadas de evaluación, más que con prácticas individualizadas de enseñanza-aprendizaje. No obstante, es evidente que las competencias de las personas pueden promoverse tanto bajo esquemas 
estandarizados como no estandarizados, tal y como se aprecia en las diferentes definiciones de competencias señaladas anteriormente, donde:

- Solo 5 (22.7\%) de las 22 definiciones hacen referencia explícita a la estandarización.

- La noción estandarizada de las competencias está lejos de ser una característica común a su conceptualización.

Es importante tener en mente que, en torno al significado de las competencias, en el ámbito educativo, laboral y social, existen culturas - a nivel de individuos, instituciones, empresas, sectores productivos, sociedades, entidades geopolíticas- que respaldan el desarrollo de complejos sistemas de formación, evaluación, certificación y aseguramiento de la calidad con base en estándares de desempeño preestablecidos.

También existen culturas que rechazan cualquier atisbo de políticas o mecanismos en ese sentido, pero asumen la adquisición y desarrollo de competencias individuales y colectivas bajo esquemas relativamente flexibles, contextualizados y poco o nada estandarizados. Asimismo, entrado el siglo XXI, aún prevalecen culturas que se oponen a cualquier enfoque de formación de competencias — tanto estandarizadas como no estandarizadas_, en aras de la preparación libre y democrática de las personas, pero que, a falta de medidas de evaluación pertinentes, corren el riesgo de exponer sus genuinos intereses y propósitos a los de la incompetencia y la simulación de individuos y grupos.

\subsection{Contexto}

Esencialmente, las competencias individuales resultan de la interacción de factores biológicos y no biológicos a lo largo de la vida (desde la concepción hasta la muerte) (Climént, 2012b). Los primeros, a partir de la dotación genética de cada persona; y los segundos, en relación con los contextos - ambientes o medios- donde tienen lugar los eventos de enseñanza-aprendizaje relevantes para la formación del propio individuo. De tal forma, en tanto el componente genético prácticamente es el mismo durante todo el ciclo biológico, el contexto de formación es -o puede ser- sumamente variable ante la infinidad de posibilidades y elementos impredecibles que lo conforman. En lo concerniente al contexto de las competencias, por lo que toca a las distintas definiciones revisadas, cabe destacar lo siguiente: 
- En general, las competencias se relacionan con uno o más de tres contextos: a) el laboral, b) el educativo y c) el social (o de la vida). Estos contextos, a su vez, determinan la connotación de las propias competencias (Climént, 2012a).

- Dieciocho definiciones conceptúan las competencias en el contexto laboral; 15, en el educativo; y solo 9, en el social. La mitad de ellas (11 de 22) se limita a uno de los tres contextos (laboral, educativo o social); 2 (Nos. 8 y 11) lo hacen en los dos primeros (laboral y educativo); y nueve (Nos. 6, 9, 10, 14, 15, 16, 18, 19 y 22) están vinculadas a cualquiera de los contextos observados (laboral, educativo y social).

Por consiguiente, el sentido y alcance de las competencias individuales -es decir, lo que las personas saben, saben hacer y pueden hacer- es consustancial a su contexto de formación (educación, capacitación y experiencia) y aprendizaje (formal, no formal e informal). Sin embargo —es conveniente advertir-, las normas o estándares de competencia, en su calidad de instrumentos de evaluación de amplia validez, se formulan de manera general al margen de contextos de formación particulares. Así, mientras la praxis evaluativa del enfoque de competencias hace por la descontextualización de los saberes, la praxis formativa — del propio enfoque - hace por contextualizarlos.

\subsection{Concepción}

Las competencias de las personas, tanto a nivel individual como colectivo, pueden abordarse en el ámbito de tres esferas: la de quienes las poseen (el lado de la oferta o proveedor); la de quienes las requieren (el lado de la demanda o beneficiario); y la que resulta de la confluencia e interrelación entre ambas (Climént, 2012a). Pese a que las competencias de individuos y grupos no pueden explicarse de fondo, al margen de esta condición bimodal oferente-demandante o proveedor-beneficiario-, es, por demás, común observar, tanto en la terminología teórica como en la concepción aplicativa del vocablo competencias, una clara tendencia a pronunciarse por una de las dos perspectivas. Evidentemente, de este sesgo como polo de atención hacia una las esferas primarias que engloban las competencias individuales y colectivas - no son ajenas muchas definiciones del término competencias:

- Casi todas las definiciones analizadas (19 de 22) asumen las competencias del lado del individuo como atributos o cualidades de este.

- En relación con los requerimientos y las expectativas de terceras personas, solo tres definiciones circunscriben las competencias individuales al lado de la demanda. 
- Únicamente en cuatro casos (las definiciones de Woodruffe, No. 5; Spencer y Spencer, No. 6; Epstein y Hundert, No. 10; y Braun et al., No. 21), la noción de competencias comprende ambos lados: el de la parte oferente y el de la parte demandante.

\subsection{Enfoque de formación}

En el argot de la floreciente cultura en torno al tema de las competencias, lo mismo se habla de ellas como habilidades que como competencias. Esta situación refleja la poca o nula comprensión del complejo significado de ambos términos dentro del no menos complejo proceso de formación (educación, capacitación y experiencia) por el que las personas eventualmente son capaces de hacer lo que se espera de ellas en el ejercicio propio de sus funciones, derechos y obligaciones bajo un determinado sistema de normas. Como obviedad sobre la diferencia entre unas y otras, baste con señalar que, en tanto las habilidades son componentes consustanciales de las competencias, estas no lo son de aquellas. Hecha esta aclaración, de vuelta al análisis de las diversas definiciones de competencias, es pertinente hacer un par de observaciones sobre la educación y la capacitación bajo este enfoque (hacia habilidades precursoras de competencias o hacia competencias, propiamente):

- Seis de las definiciones enlistadas asumen el significado de las habilidades como equivalente al de las competencias. El resto de las definiciones (16 de 22) se refiere a las competencias como tales —más allá de las habilidades-, con un sentido más amplio de su naturaleza y propiedades primarias.

- A través de los años, el significado de las competencias, lejos de simplificarse, tiende a ser más complejo, conforme se enriquece su conocimiento.

\subsection{Proceso de habituación}

La habituación se entiende aquí como el proceso a través del cual las actividades y las labores regulares de las personas, comprometidas con sus respectivas competencias y comportamientos, se convierten, eventualmente, en hábitos personales, de aprendizaje, estudio, salud y trabajo, según el caso.

El proceso de habituación tiene por virtud, propiciar la formación de sinapsis (sinaptogénesis), dentro y entre complejos constructos neurales -aprendizaje, memoria, aptitudes, destrezas, conductas-. Entramado nervioso que favorece el desarrollo de las habilidades físicas y mentales, precursoras y componentes de las competencias mismas. 
Es oportuno indicar que, gracias a las formas no declarativas o implícitas del aprendizaje y la memoria, las personas aprenden información y habilidades a través de la mera exposición o práctica, sin necesidad de esfuerzo o actividad consciente. Así, en un momento dado, llegan a "automatizarlas" (Nelson, Haan y Thomas, 2006). De ahí que, del ejercicio apropiado de esta facultad cerebral, en mucho dependen la pericia y la experiencia (expertise) alcanzadas por las personas, a lo largo de la vida, en sus respectivos campos de actividad.

De las 22 definiciones revisadas, solo una, la de Epstein y Hundert (No. 10) (2002), hace mención expresa al "ejercicio habitual y juicioso" de las funciones cognitivas vinculadas con las competencias profesionales - necesariamente relacionadas con competencias académicas de la educación superior y competencias laborales del campo de estudio-.

\subsection{Referencia a valores}

Debe tenerse presente que al valor —cualidad en mérito o estima- de las competencias subyacen los intereses de las entidades sociales y económicas involucradas (stakeholders) ${ }^{2}$ con las competencias de uno o más individuos; y que este juego de intereses, en gran medida, determina los propósitos de las competencias individuales, considerando a quienes las proveen, a quienes las demandan y a la relación entre unos y otros. En lo que respecta a las definiciones analizadas:

- Pocas definiciones (7 de las 22) se refieren directa y explícitamente a valores; la mayoría (15 de 22) los asume implícitamente, en el mejor de los casos.

- La definición de Cázares y Cuevas (No. 16) destaca la importancia de los valores en las competencias individuales al señalar que estas son: "Una interacción reflexiva y funcional de saberes [...] enmarcada en principios valorales". (2007, p. 18)

- Salvo por la definición de Epstein y Hundert (No. 10) (2002), donde se advierte la importancia de la "función afectiva/moral" de las competencias profesionales (en el ejercicio de la medicina), y la de Tobón (No. 22) (2013), que señala el desarrollo y aplicación de diferentes saberes de manera articulada y ética, no se especifica el carácter (político, económico, social, cultural, ambiental, ético) de los valores que direccionan el objetivo de las competencias; de modo que este objetivo, está sujeto a

2 A las entidades sociales y económicas con intereses en juego, en determinado asunto, iniciativa o proyecto, se les llama en inglés stakeholders. 
los intereses de los actores involucrados (stakeholders), bajo condiciones y circunstancias concretas.

\subsection{Dimensión, entre lo individual y lo colectivo}

Aunque en principio las competencias conciernen al desempeño individual, también pueden referirse al de grupos, como por ejemplo: equipos de trabajo, organizaciones (públicas, privadas y sociales), sectores productivos, economías nacionales y bloques económicos. En cualquier caso, no debe omitirse el hecho de que el desempeño de las personas repercute en el de otras, lo cual genera efectos que trascienden - por lo que se hace o deja de hacer - en distintas esferas de transformación y cambio a corto, mediano y largo plazo. En lo que respecta al análisis de las 22 definiciones recopiladas, este revela que:

- Casi todas las definiciones enfatizan la importancia de las competencias en el ámbito individual (único, independiente, aislado) y omiten el colectivo (conjunto, interactivo, grupal).

- Hay dos excepciones que, además de aludir al sentido individual de las competencias, se refieren a ellas de manera colectiva (en relación con grupos de personas): la definición de Mulder (No. 8) (2001), en lo relativo a la capacidad de una organización para alcanzar logros específicos; y la definición de Fernández-Salinero (No. 14) (2006), como la complementariedad y el encadenamiento de competencias individuales (Climént, 2012a).

\subsection{Etapa de la vida}

Frente a la idea "sincrónica" de las competencias, donde los procesos y causas que las originan se conciben de manera simultánea, es fundamental su noción "diacrónica" como constructos complejos que los individuos desarrollan a lo largo de la vida en estrecha correspondencia con su identidad personal (biológica, psicológica, social y cultural). Sobre esta diferencia conceptual es conveniente atender un par de observaciones, relativas a las definiciones anotadas:

- Si bien las competencias de las personas se forjan de manera gradual, conforme a los cambios de las facultades físicas y mentales que tienen lugar durante las distintas etapas de la formación a lo largo de la vida, esta condición solo la recogen cinco (22.7\%) de las 22 definiciones analizadas. 
- Conceptualmente, el énfasis de la formación de competencias en individuos y grupos se orienta a la juventud —en el total de las definiciones_ y a la adultez —en casi todas ellas (19 de 22)—. En ningún caso se ciñe única y exclusivamente a la infancia.

\subsection{Temporalidad}

En la medida en que las competencias de individuos y grupos son más complejas, mayores son las exigencias para aprenderlas, desarrollarlas y perfeccionarlas. Así, la integración de las competencias profesionales puede suponer años —e incluso décadas- de formación (educación, capacitación y experiencia). Este proceso se encuentra estrechamente vinculado con los cambios biológicos, sicológicos y sociales por los que las personas atraviesan en el curso de sus respectivas vidas (desde la concepción hasta la muerte), de modo que la génesis de toda competencia es objeto de un proceso evolutivo (adquisición, desarrollo, perfeccionamiento) que, bajo condiciones adversas (falta de práctica, desempleo, enfermedades, edad), puede convertirse en involutivo (insuficiencia, deformación, declive, pérdida). De ahí que, el tema de la "formación de competencias" para los educadores deba centrarse en la noción constructiva de estas, pero a sabiendas de que su trayectoria es única, impredecible e inestable en la preparación y desarrollo de las personas.

En el conjunto de las definiciones revisadas, solo dos de ellas hacen referencia a la temporalidad de las competencias individuales: la de Epstein y Hundert (No. 10) (2002), al señalar que las competencias profesionales son transitorias; y la de Braun et al. (No. 21) (2012), quienes sostienen que las competencias pueden perderse.

Frente a los cambios que acompañan a la globalización, en sus diferentes vertientes, advertir sobre la temporalidad de las competencias, desde su concepto mismo, es a todas luces un acierto. De tal modo, la temporalidad de las competencias debe reflejarse en la flexibilidad de los planes y programas de estudio de las instituciones educativas, particularmente de educación superior; y por consiguiente, en la estructura integral de los diversos tipos de competencias promovidas (aprendizajes centrales, competencias claves, competencias genéricas, competencias específicas, metacompetencias).

\subsection{Paradigma epistemológico}

Toda definición de competencias supone un acercamiento parcial a lo que estas son y representan, por lo que su conocimiento es inherente al soporte lógico de un modelo o referente teórico-metodológico sobre la génesis del propio conocimiento. 
El paradigma epistemológico científico/racionalista —predominante en el desarrollo de nuevo conocimiento en el mundo desde hace más de 200 años - sirve de soporte a muchas de las definiciones de competencia. Esta influencia es particularmente notoria durante las últimas cuatro décadas: desde los albores conceptuales, en pro del fomento extensivo de las competencias, con el conocido artículo de David McClelland (1973) hasta el establecimiento de políticas e instrumentos para el fomento extensivo de la educación y la capacitación por competencias, en grandes sectores económicos y sociales de numerosas sociedades contemporáneas.

En contraparte, el paradigma sistémico/naturalista cobra especial importancia e interés durante un periodo relativamente corto y reciente, con los inminentes trastornos asociados al cambio climático y la exacerbación de problemáticas sociales y medioambientales, que pasan de lo local hasta la escala planetaria. En cuanto al soporte epistemológico de las competencias personales, es pertinente destacar los siguientes puntos:

- Mientras quince definiciones responden al racional del paradigma científico/racionalista, "esencialmente analítico, reduccionista, empiricista, asociacionista, reactivista, nomológico y monista" (Guba y Lincoln, 1983, p. 312), solo siete de ellas se apegan a los axiomas del paradigma sistémico/naturalista, caracterizado como holista, contextual, inductivo-generalista, multidimensional e interdimensional, informal, natural, humanístico, cualitativo y receptivo-respondiente (Guba y Lincoln, 1983).

- Es interesante hacer notar, de manera particular, la inclusión de ambos paradigmas en la conceptualización de Epstein y Hundert (No. 10) (2002) y la de Braun et al. (No. 21) (2012), que apuntan al fortalecimiento de las propiedades básicas de las competencias profesionales a partir de un marco epistemológico más amplio.

- La influencia del paradigma sistémico/naturalista es evidente entre los conceptos de competencia revisados, y por lo tanto, también, de las propiedades que se les confieren, o pueden conferir, a las competencias individuales, al reemplazar o complementar al paradigma científico/racionalista en las expectativas de formación y desarrollo de las personas.

En síntesis, dentro del conjunto de definiciones y propiedades analizadas destacan las conceptualizaciones: a) no estandarizadas, b) en el contexto laboral, c) desde la perspectiva oferente, d) orientadas a competencias (más que a habilidades), e) al margen del proceso 
de habituación, f) con referencia implícita a valores, g) en el ámbito individual (más que en el colectivo), h) durante la juventud y la adultez, i) atemporales (en cuanto a la transitoriedad de las competencias) y j) sustentadas en el paradigma científico/racionalista. Sin embargo es menester aclarar-, este perfil no corresponde necesariamente con la noción que las personas tienen de las competencias, por la que se manifiestan a favor o en contra de su fomento.

Téngase en cuenta que, los estándares de competencia, en su calidad de instrumentos de evaluación, se acogen a los principios del método científico en tres aspectos centrales: a) el énfasis en las relaciones causa-efecto entre variables de interés; b) la sustracción o deslinde del fenómeno de intervención (presumiblemente universal) de las circunstancias y condiciones asociadas con realidades concretas (específicas); y c) la exaltación del valor del conocimiento científico $-\mathrm{y}$ por añadidura, del de las competencias mismas - al margen o por encima de otro tipo de valores (sociales, culturales, humanísticos, cívicos, éticos). Así, la validez y la confiabilidad de la evaluación, independientemente de los procesos y contextos de formación implicados, se tienen como principios universales para el aseguramiento de la calidad de sistemas de formación por competencias; pero, a la vez, estos principios propician, en alguna medida, el carácter reduccionista de los referentes estandarizados.

Por otra parte, a la génesis de las competencias individuales y colectivas concurren distintos eventos, procesos, contextos y valores relevantes a situaciones concretas de formación, donde los preceptos del paradigma sistémico/naturalista tienen -o debieran tener- un lugar preponderante, especialmente en lo concerniente a tareas (contextualizadas) de investigación, planeación y desarrollo formativo.

De tal modo, el positivismo contribuye en ciertos aspectos a las fortalezas del enfoque de competencias, pero en otros puede derivar en desventajas que es preciso atender —en tiempo y forma - para, en la medida de lo posible, remediarlas o compensarlas. No basta, pues, con conocer las propiedades de las competencias para establecer sus alcances y límites, es necesario, además, comprender las fortalezas y debilidades de estas propiedades.

\section{Fortalezas y debilidades}

Con el fin de ahondar en el conocimiento de la naturaleza de las competencias, así como en su significado para la formación de las personas, en el Cuadro 2 se examinan las fortalezas y debilidades de las diez propiedades analizadas anteriormente. 
Cuadro 2

Fortalezas y debilidades de las competencias en relación con sus propiedades conceptuales

\begin{tabular}{|c|c|}
\hline \multicolumn{2}{|c|}{ Estructura: Estandarizada } \\
\hline Fortalezas & Debilidades \\
\hline $\begin{array}{l}\text { - Contribuye al desarrollo de un sistema de } \\
\text { información basado en principios de validez y } \\
\text { confiabilidad que sirva a las distintas } \\
\text { entidades sociales y económicas } \\
\text { involucradas (stakeholders) en asuntos } \\
\text { relativos a las competencias individuales y } \\
\text { colectivas. } \\
\text { - Fundamenta el aseguramiento de la calidad } \\
\text { de la acreditación y la certificación de } \\
\text { competencias (académicas, laborales, } \\
\text { profesionales). } \\
\text { - Permite el reconocimiento sistematizado de } \\
\text { las competencias individuales, } \\
\text { independientemente de la forma, momento y } \\
\text { lugar en que fueron adquiridas. } \\
\text { - Aboga por esquemas de fomento a las } \\
\text { competencias a gran escala (institucional, } \\
\text { nacional, regional, internacional). } \\
\text { - Pone énfasis en resultados de aprendizaje } \\
\text { por encima de procesos. } \\
\text { - Atiende especialmente a los intereses de la } \\
\text { demanda. }\end{array}$ & $\begin{array}{l}\text { - Su desarrollo es muy sofisticado, complejo } \\
\text { y costoso. } \\
\text { - En lugar de flexibilizar los esquemas de } \\
\text { educación y capacitación puede contribuir } \\
\text { a hacerlos más rígidos y excluyentes. } \\
\text { - Contrario a lo que se espera, puede } \\
\text { desalentar la participación en el } \\
\text { aprendizaje a lo largo de la vida. } \\
\text { - Tendencia a la descontextualización de los } \\
\text { instrumentos de evaluación. } \\
\text { - Poca o nula comprensión de los procesos } \\
\text { y las condiciones que favorecen o, en su } \\
\text { defecto, dificultan el desarrollo gradual de } \\
\text { la formación de individuos y grupos. } \\
\text { - La optimización costo-beneficio está sujeta } \\
\text { a condiciones de amplia cobertura } \\
\text { (institucional, nacional, } \\
\text { internacional) y largo plazo. } \\
\text { - A falta de expansión y efectividad, su } \\
\text { implantación puede resultar } \\
\text { excesivamente costosa. } \\
\text { - Puede no ser congruente con las } \\
\text { posibilidades reales de la gestión de } \\
\text { competencias en situaciones concretas. }\end{array}$ \\
\hline \multicolumn{2}{|c|}{ Estructura: No estandarizada } \\
\hline Fortalezas & Debilidades \\
\hline $\begin{array}{l}\text { - Concierne a procesos (evaluación formativa), } \\
\text { más que a resultados (evaluación sumativa). } \\
\text { - Facilita la complementación de la praxis } \\
\text { evaluativa y la praxis formativa (se ajusta a } \\
\text { condiciones y circunstancias particulares). } \\
\text { - Su gestión es menos compleja, sofisticada y } \\
\text { costosa. }\end{array}$ & $\begin{array}{l}\text { - Las competencias pueden no estar } \\
\text { debidamente sustentadas, en lo que } \\
\text { respecta a pertinencia, vigencia, validez y } \\
\text { confiabilidad. } \\
\text { - Se descuidan los intereses de -o el } \\
\text { vínculo con- los sectores que demandan } \\
\text { o requieren las competencias de otros en } \\
\text { lo relativo, por ejemplo, a mercado de } \\
\text { trabajo y beneficiarios económicos y/o } \\
\text { sociales. }\end{array}$ \\
\hline \multicolumn{2}{|c|}{ Contexto: Descontextualizado } \\
\hline Fortalezas & Debilidades \\
\hline $\begin{array}{l}\text { - Confiere validez y confiabilidad a los } \\
\text { instrumentos de evaluación estandarizados, } \\
\text { sobre supuestos de universalidad; esto es, } \\
\text { independientemente de la forma, momento y } \\
\text { lugar en que las personas se preparan y } \\
\text { adquieren sus respectivas competencias. }\end{array}$ & $\begin{array}{l}\text { - No aporta información sobre los motivos } \\
\text { (antecedentes, procesos, circunstancias) } \\
\text { que determinan diferencias en la } \\
\text { consecución de competencias individuales } \\
\text { y colectivas de especial interés. }\end{array}$ \\
\hline
\end{tabular}




\begin{tabular}{|c|c|}
\hline \multicolumn{2}{|c|}{ Contexto: Contextualizado } \\
\hline Fortalezas & Debilidades \\
\hline $\begin{array}{l}\text { - Ubica las competencias en relación con } \\
\text { situaciones concretas de formación } \\
\text { (educación, capacitación, experiencia). } \\
\text { - Reconoce factores a favor y en contra del } \\
\text { desarrollo de competencias en situaciones } \\
\text { particulares. }\end{array}$ & $\begin{array}{l}\text { - En la medida en que se restringe la validez } \\
\text { y confiabilidad de los instrumentos de } \\
\text { evaluación no estandarizados, las } \\
\text { competencias asumidas carecen de } \\
\text { soporte. }\end{array}$ \\
\hline \multicolumn{2}{|c|}{ Concepción: Del lado del individuo (provisión) } \\
\hline Fortalezas & Debilidades \\
\hline $\begin{array}{l}\text { - Destaca aspectos asociados con las } \\
\text { competencias de individuos y grupos en el } \\
\text { ámbito de quienes las fomentan, poseen y/o } \\
\text { ejercen. } \\
\text { - Contribuye a la praxis formativa. }\end{array}$ & $\begin{array}{l}\text { - Excluye o remite a un segundo plano las } \\
\text { expectativas e intereses de terceras } \\
\text { partes, incluyendo las externalidades } \\
\text { vinculadas al uso y aplicación de las } \\
\text { competencias. } \\
\text { - Descuida la praxis evaluativa. }\end{array}$ \\
\hline \multicolumn{2}{|c|}{ Concepción: Del lado del terceros (demanda) } \\
\hline Fortalezas & Debilidades \\
\hline $\begin{array}{l}\text { - Se inclina por la noción de las competencias } \\
\text { a partir de las expectativas e intereses de } \\
\text { terceras partes. } \\
\text { - Favorece a la praxis evaluativa. }\end{array}$ & $\begin{array}{l}\text { - Omite o desatiende la concepción de las } \\
\text { competencias individuales y colectivas en } \\
\text { relación con la naturaleza y los atributos } \\
\text { físicos e intelectuales de los seres } \\
\text { humanos, así como de los procesos de } \\
\text { aprendizaje (formal, no formal e informal) y } \\
\text { formación (educación, capacitación, } \\
\text { experiencia) a lo largo de la vida. } \\
\text { - Se desvincula de la praxis formativa. }\end{array}$ \\
\hline \multicolumn{2}{|c|}{ Enfoque de formación: Con base en habilidades } \\
\hline Fortalezas & Debilidades \\
\hline $\begin{array}{l}\text { - Las habilidades (skills) son precursores y } \\
\text { componentes básicos de futuras } \\
\text { competencias para la vida y el trabajo } \\
\text { (biológica, psicológica, social y culturalmente } \\
\text { integradas), por lo que su atención y } \\
\text { desarrollo es crítico durante la infancia y la } \\
\text { juventud, y especialmente en los primeros } \\
\text { años de vida (en que el cerebro tiene un gran } \\
\text { desarrollo). } \\
\text { - Generalmente se aboca al fomento de las } \\
\text { habilidades clave (key skills, functional skills) } \\
\text { para el desarrollo de futuras competencias. }\end{array}$ & $\begin{array}{l}\text { - Mientras se presta especial atención al } \\
\text { fomento de las habilidades en uno o más } \\
\text { individuos, pueden descuidarse las } \\
\text { inclinaciones, intereses y talentos } \\
\text { personales. }\end{array}$ \\
\hline
\end{tabular}




\begin{tabular}{|c|c|}
\hline \multicolumn{2}{|c|}{ Enfoque de formación: Con base en competencias } \\
\hline Fortalezas & Debilidades \\
\hline $\begin{array}{l}\text { - Concierne especialmente a las expectativas } \\
\text { de terceras partes y de los propios sujetos de } \\
\text { competencia, en el ámbito de las estructuras } \\
\text { políticas, sociales y económicas } \\
\text { establecidas. } \\
\text { - Atañe -aunque no se advierta- al } \\
\text { conocimiento de dichas estructuras, al grado } \\
\text { de madurez (adultez) individual y al } \\
\text { desarrollo de la identidad personal. }\end{array}$ & $\begin{array}{l}\text { - Poco o nada se ve, en materia de } \\
\text { competencias, más allá de las } \\
\text { expectativas, necesidades y estructuras } \\
\text { establecidas. } \\
\text { - Puede sesgarse tanto a la praxis } \\
\text { evaluativa (por la demanda de } \\
\text { competencias), como a la praxis formativa } \\
\text { (por la gestión de competencias). } \\
\text { - Para efectos de evaluación, lo mismo que } \\
\text { de formación, no existe una comprensión } \\
\text { articulada de los precursores y } \\
\text { componentes de las competencias } \\
\text { buscadas. }\end{array}$ \\
\hline \multicolumn{2}{|c|}{ Proceso de habituación: Advertido } \\
\hline Fortalezas & Debilidades \\
\hline $\begin{array}{l}\text { - Reconoce la necesidad de la formación de } \\
\text { buenos hábitos de aprendizaje, estudio, } \\
\text { salud y trabajo para la adquisición, } \\
\text { desarrollo, perfeccionamiento de y } \\
\text { mantenimiento de competencias } \\
\text { académicas, profesionales y laborales. } \\
\text { - Promueve la interrelación constructiva entre } \\
\text { habilidades, hábitos y rutinas; productos, } \\
\text { resultados e impacto. }\end{array}$ & $\begin{array}{l}\text { - El proceso de aprendizaje y cambio en los } \\
\text { patrones de comportamiento de individuos } \\
\text { y grupos, implica determinación, disciplina, } \\
\text { dedicación y trabajo, contra la refracción al } \\
\text { cambio, condiciones que pueden ser } \\
\text { desde impopulares hasta inviables. }\end{array}$ \\
\hline \multicolumn{2}{|c|}{ Proceso de habituación: Inadvertido } \\
\hline Fortalezas & Debilidades \\
\hline $\begin{array}{l}\text { - Usualmente es más fácil y mejor visto, } \\
\text { soslayar, en lugar de afrontar, la necesidad } \\
\text { de cambios en las rutinas personales, } \\
\text { cuando se trata de la adopción de buenos } \\
\text { hábitos de aprendizaje, estudio, salud y } \\
\text { trabajo; y más aún, de reemplazar malos } \\
\text { hábitos por buenos hábitos (incluyendo } \\
\text { valores). }\end{array}$ & $\begin{array}{l}\text { - En la medida en que las personas carecen } \\
\text { de buenos hábitos de aprendizaje, estudio, } \\
\text { salud y trabajo, menor será el nivel, } \\
\text { alcance y permanencia de las } \\
\text { competencias en juego. } \\
\text { - Favorece la simulación y la incompetencia } \\
\text { en el desempeño de individuos y grupos. } \\
\text { - Demerita la interrelación constructiva entre } \\
\text { habilidades, hábitos y rutinas; productos, } \\
\text { resultados e impacto. }\end{array}$ \\
\hline \multicolumn{2}{|c|}{ Referencia a valores: Explícita } \\
\hline Fortalezas & Debilidades \\
\hline $\begin{array}{l}\text { - Declara principios o pautas que apelan al } \\
\text { sentido de las competencias en un sistema } \\
\text { de valores. } \\
\text { - Alude a intereses de las entidades } \\
\text { económicas y sociales involucradas } \\
\text { (stakeholders). } \\
\text { - Asume límites en el uso y en la aplicación de } \\
\text { las competencias. }\end{array}$ & $\begin{array}{l}\text { - Frente a las posturas a favor del uso y } \\
\text { aplicación de las competencias, con } \\
\text { determinado sentido (principios y valores), } \\
\text { generalmente existen otras opuestas, o } \\
\text { por lo menos distintas, según los intereses } \\
\text { de los stakeholders. }\end{array}$ \\
\hline
\end{tabular}




\begin{tabular}{|c|c|}
\hline \multicolumn{2}{|c|}{ Referencia a valores: Implícita } \\
\hline Fortalezas & Debilidades \\
\hline $\begin{array}{l}\text { - A las competencias individuales y colectivas } \\
\text { es inherente el mérito o valor que les } \\
\text { confiere su condición (propiedad) de poder } \\
\text { hacer, en el concierto de las partes } \\
\text { implicadas y los intereses en juego. } \\
\text { - Las competencias en sí mismas son parte de } \\
\text { un sistema de valores. }\end{array}$ & $\begin{array}{l}\text { - A falta de valores -más allá de los } \\
\text { intrínsecos-, el uso y la aplicación de las } \\
\text { competencias individuales y colectivas } \\
\text { pueden desvirtuarse y en consecuencia, } \\
\text { ocasionar trastornos y perjuicios a } \\
\text { terceros. }\end{array}$ \\
\hline \multicolumn{2}{|c|}{ Dimensión: Individual } \\
\hline Fortalezas & Debilidades \\
\hline $\begin{array}{l}\text { - Para distintos propósitos - definición, } \\
\text { estandarización, formación, evaluación, } \\
\text { certificación- aborda las competencias } \\
\text { estrictamente en la esfera individual. }\end{array}$ & - No advierte las competencias colectivas. \\
\hline \multicolumn{2}{|c|}{ Dimensión: Colectiva } \\
\hline Fortalezas & Debilidades \\
\hline $\begin{array}{l}\text { - Se centra en las competencias de grupos } \\
\text { (equipos de trabajo, organizaciones, sectores } \\
\text { productivos, poblaciones de interés). }\end{array}$ & $\begin{array}{l}\text { - Desatiende u omite la reciprocidad entre } \\
\text { las competencias individuales y las } \\
\text { colectivas. }\end{array}$ \\
\hline \multicolumn{2}{|c|}{ Etapa de la vida: Niñez } \\
\hline Fortalezas & Debilidades \\
\hline $\begin{array}{l}\text { - Fomenta el desarrollo de precursores y } \\
\text { componentes esenciales (habilidades físicas } \\
\text { y cognitivas; principios y valores) de futuras } \\
\text { competencias (individuales y colectivas), en } \\
\text { paralelo al desarrollo gradual del cerebro y al } \\
\text { aprovechamiento de periodos críticos } \\
\text { (ventanas de oportunidad) de aprendizaje. }\end{array}$ & $\begin{array}{l}\text { - Aplica, por error, las premisas de la } \\
\text { formación de competencias - propias de } \\
\text { la educación, la capacitación y la } \\
\text { experiencia en jóvenes y adultos- a la } \\
\text { educación de los niños. }\end{array}$ \\
\hline \multicolumn{2}{|c|}{ Etapa de la vida: Juventud } \\
\hline Fortalezas & Debilidades \\
\hline $\begin{array}{l}\text { - De manera gradual y articulada, continúa con } \\
\text { el desarrollo de precursores y componentes } \\
\text { básicos de competencias personales, de } \\
\text { entrada a la formación de competencias } \\
\text { genéricas y específicas. }\end{array}$ & $\begin{array}{l}\text { - Se aparta de una formación gradual, } \\
\text { coherente y flexible, centrada en el } \\
\text { aprendizaje individual, con lo cual da pie a } \\
\text { esquemas de formación más bien rígidos. }\end{array}$ \\
\hline
\end{tabular}




\begin{tabular}{|c|c|}
\hline \multicolumn{2}{|c|}{ Etapa de la vida: Adultez } \\
\hline Fortalezas & Debilidades \\
\hline $\begin{array}{l}\text { - Promueve la adquisición, desarrollo y } \\
\text { perfeccionamiento de las competencias } \\
\text { individuales y colectivas, a partir de la } \\
\text { formación (educación, capacitación y } \\
\text { experiencia) de los adultos; esto es, en } \\
\text { consideración a las características } \\
\text { biológicas, psicológicas y sociales de las } \\
\text { personas adultas. }\end{array}$ & $\begin{array}{l}\text { - Confunde los principios y pautas de la } \\
\text { educación para adultos (andragogía) con } \\
\text { los de la pedagogía infantil. }\end{array}$ \\
\hline \multicolumn{2}{|c|}{ Temporalidad: Declarada } \\
\hline Fortalezas & Debilidades \\
\hline $\begin{array}{l}\text { - Atiende el proceso de formación de } \\
\text { competencias no solo a través de sus etapas } \\
\text { de construcción y desarrollo, sino también } \\
\text { para su adaptación ante eventuales cambios } \\
\text { (positivos y negativos; personales y del } \\
\text { entorno). } \\
\text { - Promueve la flexibilidad de la formación y el } \\
\text { aprendizaje, en planes y programas de } \\
\text { estudio. }\end{array}$ & $\begin{array}{l}\text { - Abre el abanico de competencias, con la } \\
\text { incorporación de aprendizajes centrales, } \\
\text { competencias claves, básicas y } \\
\text { genéricas/transversales, así como } \\
\text { metacompetencias, a costa de la } \\
\text { concentración en las específicas. }\end{array}$ \\
\hline \multicolumn{2}{|c|}{ Temporalidad: Tácita } \\
\hline Fortalezas & Debilidades \\
\hline $\begin{array}{l}\text { - Asume la temporalidad de las competencias } \\
\text { como una condición inherente a la formación } \\
\text { y la naturaleza de estas. }\end{array}$ & $\begin{array}{l}\text { - Al margen del carácter transitorio de las } \\
\text { competencias, se concentra en } \\
\text { competencias específicas, lo cual propicia } \\
\text { la rigidez de los esquemas de formación y } \\
\text { aprendizaje. }\end{array}$ \\
\hline \multicolumn{2}{|c|}{ Paradigma epistemológico: Científico/Racionalista } \\
\hline Fortalezas & Debilidades \\
\hline $\begin{array}{l}\text { - Busca el cambio de situaciones concretas } \\
\text { (realidades diversas) a partir de premisas } \\
\text { positivistas (efectividad, validez, } \\
\text { confiabilidad, calidad, rentabilidad, } \\
\text { competitividad, universalidad) en el uso y } \\
\text { aplicación de las competencias de las } \\
\text { personas. }\end{array}$ & $\begin{array}{l}\text { - Descuida aspectos de orden multifactorial, } \\
\text { propios de los sistemas humanos de } \\
\text { acción. Es reduccionista. }\end{array}$ \\
\hline \multicolumn{2}{|c|}{ Paradigma epistemológico: Sistémico/Naturalista } \\
\hline Fortalezas & Debilidades \\
\hline $\begin{array}{l}\text { - Persigue la sustentabilidad (organizacional, } \\
\text { medio-ambiental, intergeneracional) de los } \\
\text { sistemas humanos de acción, al abordar el } \\
\text { carácter multifactorial de los fenómenos } \\
\text { naturales y sociales en el uso y aplicación de } \\
\text { las competencias individuales y colectivas. }\end{array}$ & - No es determinista. \\
\hline
\end{tabular}

Fuente: Elaboración propia a partir de la información recolectada. 
Frente al consabido carácter polisémico de las competencias, del que ofrece clara evidencia la muestra de 22 definiciones examinadas, las diferentes entidades sociales y económicas involucradas (stakeholders) en la adquisición, desarrollo, perfeccionamiento y declive de competencias individuales y colectivas, pueden adoptar una de las siguientes cuatro posturas::

1. A favor: adherirse a las iniciativas para el fomento de competencias —en función de las fortalezas (ventajas) conferidas a estas.

2. En contra: rechazar tales iniciativas -por asociarlas con las debilidades (desventajas) de las propiedades inherentes a las competencias.

3. Indiferente: mantenerse al margen de las dos posturas anteriores - a falta de interés, conocimiento y comprensión, tanto de las fortalezas (ventajas) como de las debilidades (desventajas) relacionadas con las propiedades esenciales de las competencias en juego.

4. Reflexiva: adoptar una postura objetiva y equilibrada; es decir, basada en la comprensión del significado, o los significados, con que se define a las competencias, a efecto de sopesar las implicaciones de sus propiedades, fortalezas y debilidades, en el contexto de situaciones concretas, más allá de nociones convencionales, cuando no tergiversadas o sesgadas, a favor o en contra.

Por encima de los modelos, modalidades y esquemas de enseñanza-aprendizaje adoptados, debe tenerse presente que todas y cada una de las propiedades de las competencias tienen algo que ver con la formación de individuos y grupos, por dos motivos fundamentales: primero, porque las competencias son componentes sustantivos de la formación de las personas, tanto para su desenvolvimiento en esferas políticas, sociales y laborales como para el adecuado funcionamiento de las sociedades donde viven y trabajan; y segundo, porque el curso (origen, desarrollo y declive) de las competencias individuales indefectiblemente discurre a lo largo del ciclo biológico de los seres humanos y de los procesos y eventos de aprendizaje que lo acompañan.

Entre las fortalezas y debilidades de las propiedades inherentes a las competencias existe una estrecha relación, cuyo conocimiento, además de facilitar la comprensión de las cualidades atribuidas a las competencias mismas, permite aprovechar sus ventajas y contrarrestar sus desventajas de mejor manera. 


\section{Conclusiones}

El sentido polisémico de las "competencias" da lugar a la gran diversidad de acercamientos teóricos y prácticos dirigidos a mejorar su comprensión y fomento, pero también, a la sobresimplicación generalizada de su significado y de las implicaciones concomitantes en la formación de las personas. Por ambas razones, cualquier estudio, proyecto o iniciativa que ataña a la formación (adquisición, desarrollo, perfeccionamiento) de competencias debe aclarar el significado de estas, desde su definición hasta los principios, supuestos e implicaciones que su conceptualización encierra. Para ello, puede recurrirse a alguna -o algunas - de las definiciones establecidas por políticas, experiencias 0 publicaciones previas, con lo que se abre la posibilidad de extrapolar los supuestos y fundamentos, que su significado conlleva, a condiciones y circunstancias ajenas; o bien, a optar por el planteamiento de una definición original - ad hoc - sustentada en las propiedades de las competencias que revisten especial interés y en el adecuado escrutinio de sus respectivas fortalezas (ventajas) y debilidades (desventajas), en el contexto y bajo las consideraciones del caso específico.

Por consiguiente —valga reiterar-, cualquiera que sea el motivo por el que se aborden las competencias individuales y colectivas, es preciso explicitar de manera unívoca el concepto con que estas son referidas, a fin de evitar confusiones y malos entendidos. Asimismo, para proporcionar una definición fundamentada de las competencias, acorde con las condiciones concretas de un caso particular (estudio, proyecto, programa, iniciativa, modelo, sistema, situación), en el que se incluya a los diferentes actores involucrados (stakeholders), es necesario examinar las fortalezas y debilidades de las propiedades atribuidas a las competencias en el ámbito de la definición planteada, o por plantear.

Entre las propiedades esenciales de las competencias, se analizaron diez de ellas: a) estructura (estandarizada o no estandarizada), b) contexto (laboral, educativo y/o social), c) concepción (del lado del individuo y/o del lado de terceros), d) enfoque de formación (con base en habilidades o con base en competencias), e) proceso de habituación (advertido o inadvertido), f) referencia a valores (explícita o implícita), g) dimensión (individual y/o colectiva), h) etapa de la vida (niñez, juventud y/o adultez), i) temporalidad (declarada o tácita) y j) paradigma epistemológico (científico/racionalista y/o sistémico/naturalista). Cada una de estas propiedades supone fortalezas (ventajas) y debilidades (desventajas), por lo que no existe una connotación idónea para cualquier propósito y circunstancia. 
Ante un sinfín de posibles arreglos, cada definición está sujeta a las fortalezas y debilidades de las propiedades descritas —entre otras que pudieran encontrarse-, en atención a los aspectos teóricos y prácticos de mayor interés para la parte autoral. Cabe esperar que el esquema utilizado en este estudio (Cuadro No. 2), para describir y examinar los pros y contras de las propiedades básicas de un amplio y diverso número de definiciones, sirva también para analizar otras definiciones, y especialmente, para formular concepciones que respondan apropiadamente a las condiciones y circunstancias de casos concretos. De este modo, los esfuerzos encaminados al fomento de las competencias pueden plantear versiones más sólidas - mejor argumentadas- sobre lo que estas son y representan, e inclinarse por las propiedades más comunes (dominantes), o bien, por configuraciones fuera de lo común (diferentes, no convencionales).

Las posturas de adhesión o aversión al fomento de competencias en poblaciones de interés pueden cambiar radicalmente una vez que se clarifica el concepto de competencias de que se está hablando, por lo que es preciso dilucidar las siguientes interrogantes:

- ¿El qué — significado, connotación, definición, concepto- de las competencias es consistente con el cómo, dónde y cuándo se forjan, evalúan y reconocen bajo las circunstancias del caso?

- ¿El término "competencias" se usa para referirse a expectativas de desempeño estandarizadas —independientemente de los procesos y contextos de aprendizaje implicados-, o al desarrollo potencial de las capacidades (académicas, laborales, profesionales) de individuos y grupos en situaciones dadas?

- ¿La praxis de la evaluación de competencias es consistente con la praxis de la formación de competencias o prevalece la disociación entre ambas?

- ¿Las competencias individuales y colectivas se promueven al margen de valores éticos o por el contrario, se basan en estos?

- ¿Se consideran las distintas entidades sociales y económicas con intereses en juego - en torno a las competencias - o en su defecto, se omiten de manera deliberada o por descuido, una o más de ellas?

- ¿El cometido de formación de competencias se centra en el aprendizaje (procesos) o en la evaluación (resultados); en el desarrollo colectivo o en el individual?

- ¿Se advierte la importancia del proceso de habituación y los buenos hábitos — de aprendizaje, estudio, salud, comportamiento, trabajo- para la adquisición, desarrollo, perfeccionamiento y mantenimiento de las competencias de las personas? 
- ¿Los estudiantes - por caso - en su calidad de sujetos aprendedores, poseen los hábitos necesarios para mejorar sus actuales habilidades y acrecentar competencias futuras?

- ¿La relación entre valores, habilidades y competencias es consistente - o no-con el desarrollo que guardan entre sí, a través de las distintas etapas de la formación (académica, laboral, profesional) y de la vida (infancia, juventud, adultez)?

- ¿Son considerados -o en su defecto, omitidos- los factores que eventualmente propician el declive o la pérdida de las competencias individuales?

- ¿El arquetipo epistemológico, del que deriva el racional de formación de competencias adoptado, se inclina por el paradigma científico/racionalista, por el sistémico/naturalista o por la complementación entre ambos?

Evidentemente, la respuesta a las interrogantes arriba anotadas es relevante para las políticas e intereses de formación (educación, capacitación, experiencia) de individuos y grupos en entidades organizacionales y geopolíticas de distinto orden. Más aún, el conocimiento de las fortalezas y debilidades inherentes a las propiedades del significado, atribuido a las competencias, puede servir al desarrollo de mejores políticas e iniciativas de formación, con miras a elevar sus probabilidades de éxito, en términos de calidad, efectividad, capacidad de inclusión, externalidades y razón costo-beneficio.

\section{Referencias}

Argudín, Yolanda. (2005). Educación basada en competencias. Nociones y antecedentes. México: Trillas.

Biemans, Harm, Nieuwenhuis, Loek, Poell, Rob, Mulder, Martin y Wesselink, Renate. (2004). Competence-based VET in the Netherlands: background and pitfalls. Journal of Vocational Education and Training, 56(4), 523-538. Recuperado de http://www.tandfonline.com/doi/pdf/10.1080/13636820400200268

Boyatzis, Richard. (1982). The competent manager. A model for effective performance. Nueva York: Wiley \& Sons.

Braun, Edith, Woodley, Alan, Richardson, John T. E. y Leidner, Bernhard. (2012). Self-rated competences questionnaires from a design perspective. Educational Research Review, 7(1), 1-18. 
Cázares Aponte, Leslie y Cuevas de la Garza, José Fernando. (2007). Planeación y evaluación basadas en competencias. Fundamentos y prácticas para el desarrollo de competencias docentes, desde preescolar hasta el posgrado. México: Trillas.

Cedefop. (2014). Terminology of European education and training policy. Luxenburgo: Publications Office of the European Union.

Climént Bonilla, Juan B. (2012a). El significado de los valores en las competencias individuales y colectivas. Revista Mexicana de Agronegocios, (31), 31-41. Recuperado de http://www.redalyc.org/pdf/141/14123108005.pdf

Climént Bonilla, Juan B. (2012b). Redimensionando el significado y alcance de las competencias personales. Actualidades Investigativas en Educación, 12(2), 1-28. Recuperado de http://www.redalyc.org/pdf/447/44723437006.pdf

Comisión Europea. (s.f.). Elearningeuropa.info. Glosario. Competencias. https://www.openeducationeuropa.eu/index.php?page=newsletter

Dainty, Andrew, Cheng, Mei-I y Moore, David. (2005). A comparison of the behavioral competencies of client-focused and production-focused project managers in the construction sector. Project Management Journal, 36(2), 39-48.

Delp, Peter, Thesen, Arne, Motiwalla, Juzar y Seshadri, Neelakantan. (1977). Systems Tools for Project Planning. Bloomington, Indiana: International Development Institute, Indiana University.

Epstein, Ronald M. y Hundert, Edward M. (2002). Defining and assessing professional competence. JAMA, 287(2), 226-235. doi:10.1001/jama.287.2.226

Fernández-Salinero, Carolina. (2006). Las competencias en el marco de la convergencia europea: Un nuevo concepto para el diseño de programas educativos. Encounters on Education, 7, 131-153. Recuperado de http://ojs.library.queensu.ca/index.php/encounters/article/viewFile/603/3500

Guba, Egon y Lincoln, Yvonna. (1983). Epistemological and methodological bases of naturalistic inquiry. En George Madaus y Daniel Stufflebeam (Eds.), Evaluation models: Viewpoints on educational and human services evaluation (pp. 363-382). Massachusetts: Kluwer-Nijhoff.

Gutiérrez Broncano, Santiago y de Pablos Heredero, Carmen. (2010). Análisis y evaluación de la gestión por competencias en el ámbito empresarial y su aplicación a la universidad. Revista Complutense de Educación, 21(2), 323-343. Recuperado de https://revistas.ucm.es/index.php/RCED/article/viewFile/RCED1010220323A/15112

Insaforp. (s.f.). Experiencias internacionales en competencia y certificación. Recuperado de http://www.insaforp.org.sv/index.php/competencias-laborales-cat/209-experienciasinternacionales-en-competencia-y-certificacion

Lloyd, Chris y Cook, Amanda. (1993). Implementing standards of competence. Practical strategies for industry. Londres: Kogan Page. 
McClelland, David. (1973). Testing for competence rather than for "intelligence". American Psychologist, 28(1), 1-14.

McDonald, Rod, Boud, David, Francis, John y Gonczi, Andrew. (2000). New perspectives on assessment. París: UNESCO. Recuperado de http://unesdoc.unesco.org/images/0010/001018/101855e.pdf

Miles, Matthew B. y Huberman, A. Michael. (1984). Qualitative data analysis. Beverly Hills, California: Sage.

Mir, Boris. (2006). Competencias, conocimientos, capacidades y habilidades. La Mirada Pedagógica.

Recuperado

de http://blog.lamiradapedagogica.net/2006/09/competencias-conocimientoscapacidades.html

Nelson, Charles, Haan, Michelle de y Thomas, Kathleen. (2006). Neuroscience of cognitive development. The role of experience and the developing brain. Nueva Jersey: John Wiley \& Sons.

Núñez Vega, Claudio y Rojas Ossio, Vladimir. (2003). La evaluación en un enfoque centrado en competencias. Revista Pensamiento Educativo, 33(2), 63-85. Recuperado de http://pensamientoeducativo.uc.cl/index.php/pel/article/view/265/563

Nyatanga, Lovemore, Forman, Dawn y Fox, Jane. (1998). Good practice in the accreditation of prior learning. Londres: CassellWelligton House.

OECD. (2002). Definition and Selection of Competences (DeSeCo). Theoretical and conceptual foundations. Strategy paper, Neuchâtel: Suiza.

Pimienta Prieto, Julio H. (2008). Evaluación de los aprendizajes. Un enfoque basado en competencias. México: Pearson Educación.

Spencer, Lyle y Spencer, Signe. (1993). Competence at work. Models for superior performance. Nueva York: Wiley \& Sons.

Strauss, Anselm L. (1987). Qualitative analysis for social scientists. Nueva York: Cambridge University Press.

Tobón, Sergio. (2013). Formación integral y competencias. Pensamiento complejo, currículo, didáctica y evaluación (4ª Ed.). Bogotá: Ecoe Ediciones.

Woodruffe, Charles. (1993). What is meant by a competency? Leadership and Organization Development Journal, 14(1), 29-36. 